\title{
Innovating Beyond the Fuzzy Front End: How to Use Reward-Based Crowdfunding to Co-create with Customers
}

\author{
Nikolaus Lipusch, Dominik Dellermann, Sarah Oeste-Reiß, Philipp Ebel \\ University of Kassel, Hessen, Germany \\ \{lipusch, dellermann, oeste-reiss, ph.ebel\}@uni-kassel.de
}

\begin{abstract}
Current research suggests that crowdfunding not only serves as an alternative source of capital but also as a flexible tool allowing start-ups to systematically integrate a crowd into their innovation processes. However, an adequate understanding of how start-ups can systematically leverage the co-creation potential of their early customers during crowdfunding is still nascent. Against this background, the aim of this research is to conceptualize and examine the concept of co-creation in the context of reward-based crowdfunding. In doing so, we distinguish it from other methods of user integration in the realm of open innovation and discuss how entrepreneurs can leverage reward-based crowdfunding to engage their customers in the development and deployment of their product and service offerings.
\end{abstract}

\section{Introduction}

Crowdfunding has gained considerable popularity in recent years [1]. Thus, more and more firms use crowdfunding to collect money to develop their business [2]. Recent research in the field suggests that users of crowdfunding not only participate because of financial interest, such as monetary return, but because they have a strong interest in the functionality and use of the product [3]. One type of crowdfunding that might be particularly suitable to engage potential customers is reward-based crowdfunding [4].

The reason for this is that compared to the other crowdfunding types (i.e. donation-, lending- and equity-based crowdfunding), it offers the unique possibility to engage with potential customers.

That crowds are willing and capable to participate in such activities is also supported by research. For instance, Gerber et al. [5] found that one important motive for people to participate in reward-based crowdfunding is "to make things happen". In a similar vein, research suggests that campaigns that offer supporters the possibility to participate in the development of a firms' products and services have significant effects on the market success of these firms [6].

Although the above findings provide a first hint toward reward-based crowdfunding's potential to harness the crowd for a start-up's innovation activities, research on this topic is still embryonic. Hence, there is very few research to date that discusses reward-based crowdfunding with regard to its unique properties (i.e. antecedents) that make it conducive to co-innovate with customers. Furthermore, current research fails to provide an adequate understanding as to how start-ups can systematically use reward-based crowdfunding platforms to harness the co-creation potential of early customers for their innovation activities. Therefore, we propose the following research question:

What constitutes the co-creation potential of reward-based crowdfunding platforms and which interactions and IT functionalities are needed to leverage this potential?

Consequently, the remainder of this paper is organized as follows: First, (section 2) we cover the theoretical background on crowdfunding and crowdsourcing as well as the relevant literature on reward-based crowdfunding. We then (section 3) elaborate on the co-creation potential of reward-based crowdfunding by comparing it to other co-creation methods in the realm of open innovation. In section 4 , we describe our research approach. Based on the framework proposed by Pedersen et al. [7], we next (section 5) discuss what entrepreneurs need to consider to fully leverage the co-creation potential of customers during reward-based crowdfunding. In section 6 , we provide an overview of opportunities and challenges with regard to co-creation in reward-based crowdfunding. This is followed (section 7) by outlining promising future research avenues. Finally, we end with our conclusion (section 8).

\section{Theoretical Background}




\subsection{Crowdfunding in the Context of Crowdsourcing}

In the following we discuss the concept of crowdfunding, how it relates to crowdsourcing as well as its potential to engage customers beyond funding.

Crowdsourcing denotes an IT based mechanism to engage crowds comprised of groups and individuals for the purpose of completing tasks, solving problems, or generating ideas [8]. By using crowdsourcing, companies gain access to a diverse set of knowledge allowing them to attain the critical resources that are necessary to increase their competitive advantage [9, 10]. Besides crowdvoting and crowdcreation, crowdfunding constitutes one of the main crowdsourcing forms [11-13]. Crowdfunding can thereby be defined as a company's open call to an undefined group of individuals for the provision of financial resources either in form of donations, in exchange for a certain amount of shares, or in exchange for some form of reward or voting rights [13, 14].

Crowdfunding is often used where traditional ways of financing are not available. Within a crowdfunding project, each supporter typically contributes a relatively small amount of money to a certain project. Therefore, intermediary platforms providing the necessary technological infrastructure, are used. Based on the reward that supporters receive in return for their funding, four types of crowdfunding can be distinguished: donation-based, reward-based, lendingbased, and equity-based crowdfunding [15, 16, 12]. Reward-based crowdfunding thereby differs from the other types with regard to the benefits that investors obtain for their financial contribution. Usually these benefits are tangible and take the form of nonmonetary rewards such as the product that is advertised by the campaign, mementos of the campaign, invites to events as well as the appreciation of supporters [17]. As such, reward-based crowdfunding stays in contrast to other types of crowdfunding that usually offer no or non-tangible rewards (i.e. donation-based crowdfunding) or even a monetary return (i.e. lendingand equity-based crowdfunding).

Apart from its main function, crowdfunding seems to hold a considerable potential beyond funding. Schwienbacher and Larralde [13], for example, compare crowdfunding to crowdsourcing thereby implying that firms can use it to obtain ideas, feedback and solutions from potential customers to then develop and support their corporate activities. A similar view is provided by Belleflamme et al. [14] who argue that since crowdfunding facilitates direct interaction between entrepreneurs and potential customer it allows firms to call upon the crowds expertise and time. In doing so, start-ups can use crowdfunding to actively engage customers in a variety of tasks such as (pre)sale marketing, market research as well as other activities that facilitate the co-creation of value with their customers (e.g. user innovation and mass customization) $[18,19]$.

\subsection{Reward-based Crowdfunding and its Potential beyond Funding}

One type of crowdfunding that is considered particularly suitable to leverage the crowd to generate additional value beyond funding is reward-based crowdfunding $[20,13,4]$. The reason for this suitability is that reward-based crowdfunding has certain characteristics that make it particularly conducive to engage with potential customers.

One main characteristic of reward-based crowdfunding is that it usually revolves around consumer goods and services. Therefore, it is perfectly suited to draw upon potential customers as co-creators for a start-up's value-creation process. Another important feature of reward-based crowdfunding is that it is based on a preselling agreement. This means that firms using reward-based crowdfunding allow supporters, due to their financial contributions, to either acquire the rights for a certain product or the rights associated with a certain product (i.e., the product itself or the rewards discussed earlier) even before it has been produced. While such a preselling agreement comes with a certain risk (i.e., that the business will be out of money before the product can go into production), it also offers certain chances for firms and customers. As the product is usually not in production by that time, new venture can use this arrangement to engage customers in the development and commercialization of their product and service efforts. This, in turn, allows them to draw on potential customers as a valuable resource for their innovation activities. Finally, compared to equity-crowdfunding reward-based crowdfunding (compared to other crowdfunding types) is often characterized by low contribution thresholds (i.e. minimum investment sums) which makes it easier for interested customers to participate in such campaigns [21].

Moreover, recent research lends first empirical evidence that reward-based crowdfunding is in fact suited for firms to harness supporters for value cocreation. Thus, research suggests that users of rewardbased crowdfunding not only participate because of financial interest, such as monetary return, but because they have a strong interest in the functionality and use of a service or product. Similar to user motivations in other open innovation contexts, they are motivated to participate because they want the product or service to 
reflect their needs [22, 3]. Further research suggests that reward-based crowdfunding platforms can be used as a marketing tool for purposes such as generating direct sales with customers, engaging customers in promotional activities, and creating new product ideas [23]. Finally, but most importantly, Stanko and Hennard [21] are able to show that feedback obtained from customers is positively related to a firm's innovation focus and product market success.

\section{Conceptualizing Co-creation in the Context of Reward-based Crowdfunding}

Co-creation marks the shift from traditional market concepts where users are seen as mere consumers to more customer-centric approaches where they are considered to be a source of value creation [24-28]. At the heart of this transition are new interaction types that allow to transfer innovative solutions from the users' domain to the companies' domain, thereby unlocking new sources of competitive advantage. Consumers can hereby contribute at various stages of a firm's value creation process, and these contributions can take on various forms from ideas to early product concepts or marketing campaigns [29-31]. While, as we have pointed out, crowdfunding may constitute one example of this growing phenomenon, it is important to note that there are also a number of other methods that companies can use to systematically leverage the potential of customers for value creation [32, 33]. Popular examples include lead user workshops, focus groups, idea competitions, idea communities, and toolkits for innovation. With crowdfunding representing another solution to co-create value with customers, one might ask how it differs compared to other co-creation methods (for an overview see [34]). Thus, in order to provide entrepreneurs with an adequate understanding about the potential benefits of co-creating with customers in reward-based crowdfunding, we precede by comparing it to other cocreation contexts in the realm of open innovation.

In contrast to the majority of open innovation methods mainly focusing on the fuzzy front end (i.e. tasks such as ideation), co-creation in reward-based crowdfunding typically revolves around the later phases of a start-up's product development process (see Figure 1). The reason for this is that reward-based crowdfunding usually revolves around early prototypes or first marketable products, meaning that the focus does not lie on tasks such as ideation but rather on tasks such as product testing, refinement, and commercialization. This has some important ramifications.

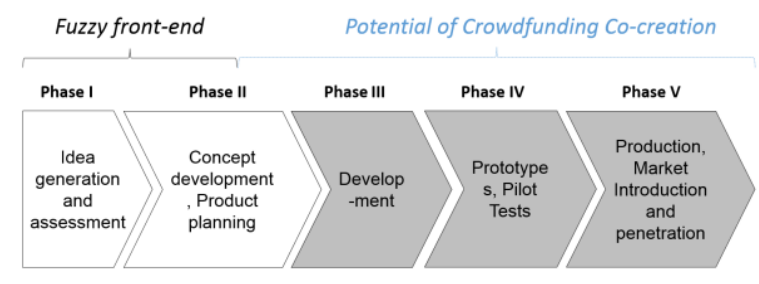

Figure 1. New Product Development Process (adapted from Herstatt \& Verworn [35])

Thus, by being able to showcase a first tangible product instead of an idea puts a start-up in the position to co-create with actual customers (also self-selection of individuals). This stands in contrast to other cocreation methods that focus on a fuzzy idea and typically make use of lead users or experts that are not representative of a company's main market. Naturally, a more advanced offering is associated with lower risk as it is less likely to change and provide customers with a clear notion of what to expect. Apart from that, a full-fledged offering allows users to invest in a campaign not only creatively (i.e. because of joy and fun) but also financially (i.e. because they have a financial interest). It can therefore be argued that people who are ready to invest in the product are also more likely to buy it and therefore might constitute actual customers in the end [36]. Moreover, the platform grants access to an existing crowd with specific capabilities.

The second difference mainly relates to the assessment quality that pertains to reward-based crowdfunding as a co-creation mechanism. Thus, compared to other co-creation methods (see table 2) that are conducted under high uncertainty and with restrictive information (i.e. they usually revolve around early ideas that are discussed with a small group), cocreation in the context of crowdfunding offers the potential to co-create with customers under more realistic conditions. The reason for this is the information available to customers during rewardbased crowdfunding [37]. Thus, people are not only provided with information on the product or service but they are also provided with information on the new venture and the business model (i.e. the team, partners, endorsements) surrounding the product. Additionally, reward-based crowdfunding platforms also allow to take into account broader environmental conditions when co-creating with a customers as they provide social information such as, for example, the hitherto acquired funding or the opinions and comments of other users [17]. A further aspect contributing to the high assessment quality of co-creation during rewardbased crowdfunding is the provision of information on different constellations of a firm's value offerings and 
the related prices which can be used to gather a more realistic estimate on the demand of the new venture's offering [14, 21]. Thus, the rich information environment of reward-based crowdfunding allows new ventures to co-create under more realistic conditions, thereby, also gaining a more reliable assessment of its offerings.

Another advantage of reward-based crowdfunding as a method to co-create with customers refers to the existing infrastructure it offers to firms to co-create with their customers [38]. This stands in contrast to other methods such as lead user workshops, focus groups, idea communities, or toolkits for user innovation that require significantly higher set-up costs (i.e. a venture must set up these methods on its own), usually without providing entrepreneurs the reach and flexibility that crowdfunding platforms would allow. Thus, in the case of reward-based crowdfunding, entrepreneurs are granted access to a crowd of customers with varying skills and capabilities without incurring the costs of building up a platform from anew. In line with this, using reward-based crowdfunding for co-creation with customers might constitute an approach capable of reducing the costs of maintenance (i.e. effort of keeping the crowd engaged) as compared to using company owned platforms [39]. In this regard, the usage of reward-based crowdfunding platform enables start-ups to engage with their supporters in an episodic way without being dependent upon continuous community management activities.

In addition to that, co-creation in the context of reward-based crowdfunding also allows a higher richness of support. Thus, reward-based crowdfunding can be used for a variety of activities such as information search, configuration of products and services, fulfillment, and consumption [24, 24]. As a result of this, co-creation in the context of rewardbased crowdfunding seems to better reflect the holistic notion of co-creation introduced by Prahalad \& Ramaswamy [24] in so far as it allows customers to individually decide at which stage and by which means (i.e. activities) they want to support a venture's value creation process [24]. This stands in contrast to other methods such as for example idea communities, idea contests, and lead user workshops that often focus on single activities (e.g. ideation) and rely on pre-selection mechanisms to determine which users can co-create at subsequent stages of a start-up's innovation process (see Table 2). On the other hand, the openness and flexibility of reward-based crowdfunding platforms with regard to co-creation may result in individual contributions that mutually support and consequently result in a more powerful and effective co-creation mechanism (also see [40] ). Table 2 provides a comparison of crowdfunding to other co-creation methods in the realm of open innovation methods with regard to the just discussed properties.

Table 1. Comparison of Co-creation Methods

\begin{tabular}{|c|c|c|c|c|}
\hline & 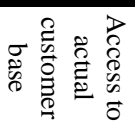 & 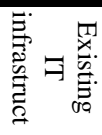 & 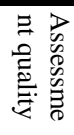 & 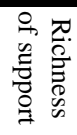 \\
\hline $\begin{array}{ll}\text { Lead } & \text { User } \\
\text { Workshop } & \\
\end{array}$ & $\mathrm{O}$ & $\mathrm{O}$ & $\mathrm{O}$ & 0 \\
\hline Focus Group & $\mathrm{O}$ & $\mathrm{O}$ & $\mathrm{O}$ & $\mathrm{O}$ \\
\hline $\begin{array}{l}\text { Ideas } \\
\text { Competition }\end{array}$ & $\mathrm{O}$ & $\theta$ & $\theta$ & $\theta$ \\
\hline Ideas Community & $\mathrm{O}$ & & $\theta$ & $\theta$ \\
\hline $\begin{array}{l}\text { Toolkits for User } \\
\text { Innovation }\end{array}$ & 0 & & $\theta$ & $\theta$ \\
\hline $\begin{array}{l}\text { Crowdfunding } \\
\text { (Reward-based) }\end{array}$ & 0 & 0 & 0 & 0 \\
\hline
\end{tabular}

\section{Research Approach}

To support a better conceptual understanding of cocreation in the context of reward-based crowdfunding as well as to provide a structure for our analysis of the phenomenon, we make use of a framework proposed by Pedersen et al. [7]. The framework which was originally used to examine the phenomenon of crowdsourcing in IS research is comprised of six elements, namely: problem, people, process, technology, governance, and outcome.

However, for the purpose of our study, we slightly adapted the framework (see figure 2). To this end, we follow a procedure similar to that proposed by Love \& Hirschheim [41] who had adapted Pedersens framework by certain dimensions of Leavitt's [42] four component model. Thus, we replace the dimension process by the dimension task. We do so because this dimension seems to more accurately fit our research goal thereby allowing us to examine our phenomenon of interest at a more fine granular level. Consequently, we derive the framework depicted in Figure 2 which serves as our starting point to closely examine cocreation during reward-based crowdfunding.

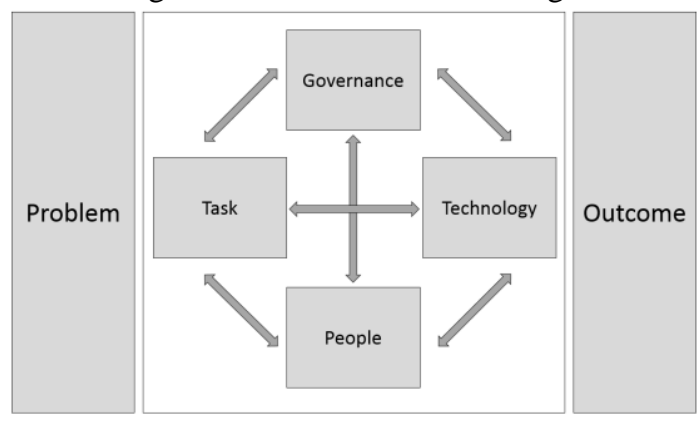


Figure 2. Proposed Research Framework (Pedersen et al. 2013)

In a next step, we apply the derived framework to a typical crowdfunding process (see figure 3 ). In this regard, we rely on the process proposed by Beaulieu et al. (2015) [43] who distinguish between three phases of a crowdfunding campaign: ex-ante, during campaign, and ex-post. Their proposed crowdfunding process covers the last two phases and consists of the following five process steps: discovery, during campaign communication, contribution, reward fulfillment, and ex-post communication. We use this process since it is, as far as our knowledge is concerned, one of the few empirically validated crowdfunding processes published so far. Additionally, the proposed process allows us to examine co-creation in the context of reward-based crowdfunding at a more fine granular level as it is enabling us to zoom in at every single process step of the proposed crowdfunding process.

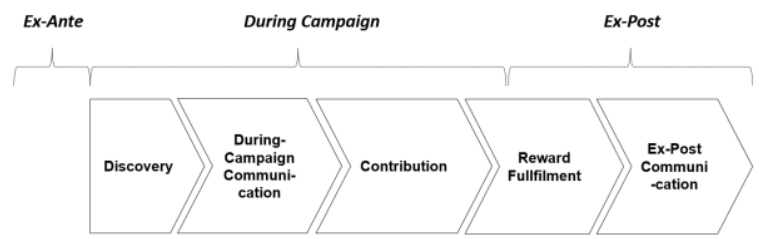

Figure 3. Crowdfunding Process adapted from Beaulieu et al. (2015)

Consequently, for each process step (see figure 3) we discuss the likely inputs and outputs that are determined by the four dimensions of our framework: task, governance, people, and technology. Problems thereby refer to the potential issues faced at each process step and the requirement of certain actions taken to resolve these issues and achieve a particular outcome. Tasks denote single work steps that can be outsourced to a crowd with the aim of supporting each process step. Governance refers to analyzing management related issues such as for example the selection of appropriate incentives, task definition and decomposition, quality assurance, and community management. People denote the different people involved as well as the roles that people take (usually the entrepreneur and a crowd) when engaging in cocreation at the different steps of crowdfunding. Technology covers the infrastructure that is required to facilitate co-creation at each process step.

\section{Organizing Co-Creation in Reward- based Crowdfunding}

Examining the process step of discovery, the main problem to be addressed at this stage is to identify potential customers as well as to find out about their respective needs. The main role of the project owner (i.e. usually the entrepreneur) is thereby to test one's assumptions about the start-up's offering. The tasks associated with this role are the creation of a landing page containing a short and concise representation of a start-up's offering as well as the formulation of questions that help to validate, test, and refine the offering. The role of a crowd is to discover the offering and to critically reflect if it does meet the requirements. The tasks associated with this concern voting and providing qualitative feedback on a venture's offering. The technologies involved in this process step are content management systems employing rating and feedback mechanisms. Typically, those are an integral part of a crowdfunding website and can also be used prior to the actual funding phase. Governance at this stage should be preoccupied with the question as how to facilitate change among the company (this entails employees as well as the management). This is important in order to get internal employees to commit to the openness introduced by the co-creation paradigm as well as to create the trust that is necessary to ensure the engagement of a crowd of customers. The outcome of this process step is feedback that helps a project owner to validate his concept and informs him or her about possible adjustments that need to be made in addition to the firm's current offer. One example of how this discovery step could be arranged is kickstarter's recently introduced functionality of live streaming which allows entrepreneurs to conduct live product presentations and FAQs with their customers.

One of the main problems that needs to be addressed in the process step of during campaign communication is to diffuse a start-up's offering by creating awareness and attention among a large crowd of potential customers. The role of the project owner is hereby to promote and advertise the venture's campaign among potential customers as well as to get them to promote the campaign themselves. Tasks associated with this are the appropriate selection of methods and tools to identify the most influential customers, thereby creating an interesting content in the form of media rich presentations (e.g. imaginative videos) and the use of social media to promote this content. The main role of a crowd is to act as a multiplier by promoting the campaign through word of mouth. The tasks associated with this affect the use of social media (e.g. twitter and Facebook) to create awareness, build trust and recommend the offer in one's social network and beyond. The technologies facilitating this process are mainly social media 
functions that are integrated into most crowdfunding websites and external tools such as, for example, Thunderclap which can help to amplify the viral dissemination through leveraging social network effects. Governance at this point should be preoccupied with the question as how to ensure that customers comply with a firm's larger goal as well as how ensure rules of conduct with regard to communication. Regarding the outcome of this particular process step, the aim is to achieve viral marketing effects (e.g. positive word of mouth) that help create wide awareness among potential supporters as well as to generate early sales.

Regarding the process step of contribution, the main problem to be addressed at this stage is how to enable and encourage customers to partake in a startup's value creation process. The role of the project owner at this stage is to clearly communicate what kind of contribution is sought. Moreover, it is his task to organize the co-creational activities of a crowd. The tasks associated with this are meant to create an adequate understanding of the product (i.e. product presentation) and to clearly state how users can contribute (i.e. by engaging in a discourse with other users). Furthermore, it is important to remind people of their role as co-creators as well as to provide them with regular feedback to encourage recurrent co-creation. The role of a crowd is to contribute to a firm's value creation process by making use of their knowledge, skills, and resources. Tasks associated with this are voting, ideating, engaging in new product development, as well as providing financial support. The technologies enabling these different kinds of participation include online payment systems, community's wikis, forums and rating mechanisms (e.g. Likes) that are usually integrated into the crowdfunding website. Governance at this stage should mainly be dealing with issues relating to adequate task decomposition and task aggregation (i.e. how individual contributions add up together to deliver the intended value), incentive selection, as well as the management of intellectual property rights and decisions rules. The outcome to be attained is a users' contribution aiming to help support a new venture in its value creation process. One example for how such a contribution can be arranged is provided by the coolest cooler - a state of the art cooling box. Thus, by initiating an open call for participation, the campaign owner asked his potential customers to comment on their most preferred product functionalities. The most frequent comments were finally incorporated into the products design [44].

Another area of value creation involves the process step of reward fulfillment. The main problem to be addressed at this stage is to ensure adequate fulfillment of a start-ups offering or the rewards associated with that offering (i.e. to make sure that the reward is getting produced and delivered on time and to the specified terms and conditions). The role of the project owner at this stage is to coordinate all activities (i.e. scheduling, production and delivery) related to the reward fulfillment. Tasks associated with this are the scheduling, production, and delivery of the reward as well as the identification of users that could help to improve a firm's fulfillment process. The role of a crowd is to act as valuable support during the reward fulfillment. Tasks associated with this are the provision of information about new markets, local deliverers, as well as local delivery terms and conditions (customs, taxes, legal terms etc.). Further tasks include the establishment of contacts (e.g. to local deliverers) as well as the provision of labor. As regards the technology it is important to provide a forum that allows discourse between entrepreneur and a crowd to jointly tackle problems associated with the reward fulfillment. Additionally, it is important to set up a communication channel beyond the platform (e.g. Mail) for the exchange of more sensitive information (i.e. business contacts). Governance at this point should be concerned with issues such as how to implement adequate quality assurance mechanisms that help to identify problems with regard to reward fulfillment. The outcome of this process step is to attain a crowd-based customer support to guarantee adequate reward delivery. One example that illustrates the above point constitutes the case of the pebble smart watch in which the crowd was used to translate regulatory on international customs and tariffs to resolve delays in shipment [45].

If we consider the process step ex-post communication at the end of the crowdfunding process, the main problem that needs to be addressed is to build up long lasting relationships with customers in order to leverage them for further co-creational activities. The role of the project owner is hereby the management of the existing customer base by continuously engaging a crowd. Tasks associated with this concern the handling of customer inquiries (e.g. complaints and warranties). Further tasks include the planning of promotional activities (e.g. online events that inform customers about new offers) with the aim to involve a crowd in the long run. The role of a crowd is to act as an advocate and promoter of a firm's offer. Tasks associated with this include the formulation of customer reviews as well as the provision of evaluations of the products and services provided by the new venture. This is especially important because one wants to involve customers as reference customers. The technology involved in this process steps includes commentary functions and social media that are 
integrated into a crowdfunding website. However, at this stage it becomes increasingly important for startups to set up communication channels and routines that can be used to reach customers even after they have left the crowdfunding website. Governance at this stage should be dealing with the issue of creating adequate community norms (i.e. a sense of belongingness). The outcome to be attained is prolonged customer involvement and support as well as a positive company image.

\section{Opportunities and Challenges of Co- Creation in Reward-based Crowdfunding}

One of the main challenges in applying co-creation to the context of reward-based crowdfunding might be that it is not perceived as a co-creation environment. Thus, while the majority of people (i.e. people with a fixed mindset) seem to view crowdfunding as a way to solely raise capital, only a small number of people (i.e. people with a growth mindset) seem to perceive crowdfunding as an opportunity to develop their product with the market [46]. This is also underpinned by our literature review which suggests that research on crowdfunding's potential beyond funding is still scarce. Nevertheless, we believe that applying this new co-creation lens could greatly benefit crowdfunding research and practice. Thus, in the recent past, a rising number of crowdfunded start-ups attracted attention mainly through negative headlines. One example is Juicero, a silicon valley rooted start-up, that has invented a juicer that is apparently not needed to consume the juice that comes with it. The case of Juicero is representative for a large number of crowdfunding campaigns that simply failed to deliver upon customer expectations. In cases like this, advocating the co-creation potential of crowdfunding might in fact constitute a promising solution. Thus, getting entrepreneurs to perceive crowdfunding as a holistic development environment might increase their likeliness to use crowdfunding to co-create with potential customers. This in turn might result in products and services that better reflect customer's needs and increase a start-ups market success. Furthermore, getting entrepreneurs to consider additional benefits of crowdfunding might lead those who previously shied away from using crowdfunding to reevaluate and reconsider their decision.

A second challenge to leverage co-creation in the context of reward-based crowdfunding might concern the current state of crowdfunding information systems. For example, Gierczak [19] remarks that there is still relatively little understanding as to how IT systems must be adapted to fully leverage the potential of co- creation in crowdfunding information systems. While current systems are theoretically designed to support start-ups at various stages of their value creation process as discussed above, system design might be still too immature to capitalize on the full potential of co-creation in crowdfunding. One example is the commentary and the update functions of crowdfunding platforms that are still used rather infrequently by entrepreneurs and supporters [47]. The root of this problem very likely lies in the challenge discussed earlier, namely that reward-based crowdfunding is not perceived as a holistic co-creation tool yet. Unfortunately, this fact seems to hold true not only for users but also for designers of such systems. Against this background, it is important to create an appropriate understanding of the proposed concept among designers so that they can develop systems that serve the purpose of co-creation even better. One way for designers to engage people in co-creational actives beyond funding must be to design more flexible participation architectures (see [48]). Participation architectures thereby refer to sociotechnical systems and design elements that encourage and integrate contributions made by participants on open online platforms [49-51]. Such design elements need to consider the evolutionary process of co-creational activities as well as the different motivations of people engaging in these activities. For example, solutions could include the incorporation of multiple tiered rewards along the steps of a venture's value creation process. Thus, to create more efficient crowdsourcing systems, it is important to reward not solely the final outcome but also the contributions that led to this step. In other words, crowdfunding systems must be designed to also reward users who contribute through other efforts such as for example the provision of ideas, feedback, or word of mouth.

\section{Future Research Avenues}

Since this research is the first attempt to conceptualize co-creation in the context of rewardbased crowdfunding there is plenty of room for future research. In the following, we identified three possible research avenues.

Because of its holistic and dynamic nature, cocreation during reward-based crowdfunding is very likely to impose new challenges to managing a crowdfunding process. Thus, firms need to take into account new kinds of customer claims regarding the access, transparency, and participation to their value creation processes [24, 52]. Consequently, successful adoption of this new paradigm will likely require significant changes in a start-up's mindset as well as in its organizational capabilities (e.g. incentives, task 
structure, management, and intellectual property). [9, 38, 53]. For example, the start-up Tinker Bots which used crowdfunding for its marketing efforts chose the radical step to engage its entire team in order to be able to efficiently manage its crowdfunding campaign [54]. As one can see from this example, managing cocreation during crowdfunding often requires a start-up to commit all of its resources to achieve a certain goal. However, many start-ups may lack the necessary resources and capabilities to fully manage such a complex and dynamic process [55]. Thus, strategies on how start-ups can effectively orchestrate this type of co-creation under consideration of resource constraints are an important issue of future research. Firms that plan to interact with crowdfunding platforms must be willing to dedicate a lot of effort, not just toward creating a project that appeals to potential supporters but also to providing these supporters with product fundraising and development updates.

The high involvement of users in co-creational activities during crowdfunding may lead to an increased sense of psychological ownership of users over their contributions and consequently a firm's decisions [56, 57]. By this increased ownership, feelings of customers may also affect a start-up's development plans and activities. Thus, co-creation shifts decision power that was formerly exercised by managers to customers, thereby blurring the boundary between these two groups. While such a strategy can bring benefits to the venture in the form of more engaged customers, it could also backfire if customers start to get too attached to certain decisional outcomes. Thus, prior research could show that companies who employ a high degree of customer integration often face difficulties in altering and changing their operations as well as responding to competitors [58]. Against this background, future research is needed to better understand both the positive and negative effects that may accrue from co-creating with customers during reward-based crowdfunding campaigns.

[1] Massolution, C.L., "Crowdfunding Industry Report", 2015.

[2] Haas, P., I. Blohm, and J.M. Leimeister, "An empirical taxonomy of crowdfunding intermediaries", 2014.

[3] Bretschneider, U. and J.M. Leimeister, "Not just an ego-trip: Exploring backers' motivation for funding in incentive-based crowdfunding", The Journal of Strategic Information Systems, 2017.
By examining co-creation in the context of rewardbased crowdfunding, this research suggests that users form an important source of a new venture's competitive advantage beyond the mere provision of funds. Thus, start-ups that understand how to successfully leverage co-creation during reward-based crowdfunding can gain access to important resources and user capabilities (i.e. skills and knowledge) that can supplement their internal value creation capabilities. [59-61]. However, the final value that is to be derived from these co-creation-based capabilities is likely to depend on attributes such as their distinctiveness and non-imitability. Thus, there might be some customers who provide rather generic resources (e.g. funding) as compared to customers who may provide strategically important and more distinct resources (e.g. information about future trends and possible solution technologies). Against this background, future research should be dedicated to examine different capabilities of co-creators in crowdfunding and examine how each of these capabilities can be deployed to increase a new venture's competitive advantage.

\section{Conclusion}

The goal of this research paper has been to introduce reward-based crowdfunding as a new way to co-create value with customers. To this end, we draw attention to certain characteristics of reward-based crowdfunding that make it particularly conducive for start-ups who want to co-create value with customers in later stages of their product development process. Moreover, we provide entrepreneurs with a guideline that helps them to assess what they need to consider when using reward-based crowdfunding for the purpose of co-creating value with their customers.

\section{References}

[4] Belleflamme, P., T. Lambert, and A.

Schwienbacher, "Individual crowdfunding practices", Venture Capital, 15(4), 2013, pp. 313-333.

[5] Gerber, E.M., J.S. Hui, and P.-Y. Kuo, eds., Crowdfunding: Why people are motivated to post and fund projects on crowdfunding platforms, 2012.

[6] Stanko, M.A. and D.H. Henard, "How Crowdfunding Influences Innovation", MIT Sloan Management Review, 57(3), 2016, p. 15.

[7] Pedersen, J., D. Kocsis, A. Tripathi, A. Tarrell, A. Weerakoon, N. Tahmasbi, J. Xiong, W. Deng, O. Oh, 
and G.-J. de Vreede, eds., Conceptual foundations of crowdsourcing: A review of IS research, IEEE, 2013.

[8] Brabham, D.C., "Crowdsourcing as a model for problem solving: An introduction and cases", Convergence, 14(1), 2008, pp. 75-90.

[9] Prpic, J. and P. Shukla, "The theory of crowd capital", 2013.

[10] Hong, L. and S.E. Page, "Groups of diverse problem solvers can outperform groups of high-ability problem solvers", Proceedings of the National Academy of Sciences of the United States of America, 101(46), 2004, pp. 16385-16389.

[11] Howe, J., "The rise of crowdsourcing", Wired magazine, 14(6), 2006, pp. 1-4.

[12] Wieck, E., U. Bretschneider, and J.M. Leimeister, "Funding from the crowd: An internet-based crowdfunding platform to support business set-ups from universities", International Journal of Cooperative Information Systems, 22(03), 2013, p. 1340007.

[13] Schwienbacher, A. and B. Larralde, "Crowdfunding of small entrepreneurial ventures", 2010.

[14] Belleflamme, P., T. Lambert, and A. Schwienbacher, "Crowdfunding: Tapping the right crowd", Journal of business venturing, 29(5), 2014, pp. 585-609.

[15] Frydrych, D., A.J. Bock, T. Kinder, and B. Koeck, "Exploring entrepreneurial legitimacy in reward-based crowdfunding", Venture Capital, 16(3), 2014, pp. 247269.

[16] Bradford, C.S., "Crowdfunding and the federal securities laws", 2012.

[17] Thies, F., M. Wessel, and A. Benlian, "Understanding the dynamic interplay of social buzz and contribution behavior within and between online platforms-evidence from crowdfunding", 2014.

[18] Belleflamme, P., T. Lambert, and A. Schwienbacher, "Crowdfunding: An industrial organization perspective", 2010.

[19] Gierczak, M.M., U. Bretschneider, P. Haas, I. Blohm, and J.M. Leimeister, "Crowdfunding: Outlining the New Era of Fundraising", Crowdfunding in Europe: State of the art in theory and practice, 2015, pp. 7-20.

[20] Belleflamme, P. and T. Lambert, "Crowdfunding: Some empirical findings and microeconomic underpinnings", 2014.
[21] Stanko, M.A. and D.H. Henard, "How Crowdfunding Influences Innovation", MIT Sloan Management Review, 57(3), 2016, p. 15.

[22] Bretschneider, U., J.M. Leimeister, and L. Mathiassen, "IT-enabled product innovation: Customer motivation for participating in virtual idea communities", International Journal of Product Development, 20(2), 2015, pp. 126-141.

[23] Brown, T.E., E. Boon, and L.F. Pitt, "Seeking funding in order to sell: Crowdfunding as a marketing tool", Business Horizons, 60(2), 2017, pp. 189-195.

[24] Prahalad, C.K. and V. Ramaswamy, "Co-creation experiences: The next practice in value creation", Journal of interactive marketing, 18(3), 2004, pp. 5-14.

[25] Normann, R. and R. Ramirez, "Werte schaffen mit Kunden und Lieferanten", Harvard Business Manager: Theorie und Praxis des Managements, Bd, 16, 1994, pp. 53-64.

[26] Wikström, S., "The customer as co-producer", European journal of marketing, 30(4), 1996, pp. 6-19.

[27] Tseng, M.M. and F.T. Piller, "The customer centric enterprise", in The customer centric enterprise, Tseng Mitchell M. and F.T. Piller, Editors. 2003. Springer.

[28] Piller, F., R. Reichwald, and M.M. Tseng, "Editorial", International Journal of Mass Customization, 1(2), 2006, pp. 157-165.

[29] Nambisan, S. and P. Nambisan, "How to profit from a better'virtual customer environment'", MIT Sloan Management Review, 49(3), 2008, p. 53.

[30] Gales, L. and D. Mansour-Cole, "User involvement in innovation projects: Toward an information processing model", Journal of engineering and technology management, 12(1-2), 1995, pp. 77109.

[31] Carbonell, P., A.I. Rodríguez-Escudero, and D. Pujari, "Customer involvement in new service development: An examination of antecedents and outcomes", Journal of product innovation management, 26(5), 2009, pp. 536-550.

[32] Tapscott, D. and A.D. Williams, Wikinomics: How mass collaboration changes everything, Penguin, 2008.

[33] Seybold, P.B., Outside innovation, HarperCollins e-books, 2014.

[34] Bretschneider, U. and S. Zogaj, "Exploring Strategies for Capturing Customer's Tacit Knowledge in Customer Integration Methods", International 
Journal of Knowledge Management (IJKM), 12(2), 2016, pp. 1-19.

[35] Herstatt, C. and B. Verworn, "The 'fuzzy front end'of innovation", in Bringing technology and innovation into the boardroom. 2004. Springer.

[36] Riedl, C., I. Blohm, J.M. Leimeister, and H. Krcmar, "Rating scales for collective intelligence in innovation communities: Why quick and easy decision making does not get it right", 2010.

[37] Agrawal, A., C. Catalini, and A. Goldfarb, "Some simple economics of crowdfunding", Innovation Policy and the Economy, 14(1), 2014, pp. 63-97.

[38] Prpic, J. and P. Shukla, "Crowd science: Measurements, models, and methods", 2016.

[39] Prpić, J., P.P. Shukla, J.H. Kietzmann, and I.P. McCarthy, "How to work a crowd: Developing crowd capital through crowdsourcing", Business Horizons, 58(1), 2015, pp. 77-85.

[40] Jeppesen, L.B. and K.R. Lakhani, "Marginality and problem-solving effectiveness in broadcast search", Organization science, 21(5), 2010, pp. 10161033.

[41] Love, J. and R. Hirschheim, "Crowdsourcing of information systems research", European Journal of Information Systems, 26(3), 2017, pp. 315-332.

[42] Leavitt, H.J., "Applied organizational change in industry: Structural, technological and humanistic approaches", Handbook of organizations, 1144, 1965, p. 1170.

[43] Beaulieu, T., S. Sarker, and S. Sarker, "A conceptual framework for understanding crowdfunding", Communications of the Association for Information Systems, 37(1), 2015, pp. 1-31.

[44] Revolution of Innovation Management, Springer, 2017.

[45] Lehner, O.M., E. Grabmann, and C. Ennsgraber, "Entrepreneurial implications of crowdfunding as alternative funding source for innovations", Venture Capital, 17(1-2), 2015, pp. 171-189.

[46] Giones, F. and P. Oo, "How Crowdsourcing and Crowdfunding are Redefining Innovation Management", in Revolution of Innovation Management. 2017. Springer.

[47] Mollick, E., "The dynamics of crowdfunding: An exploratory study", Journal of business venturing, 29(1), 2014, pp. 1-16.

[48] Majchrzak, A. and A. Malhotra, "Towards an information systems perspective and research agenda on crowdsourcing for innovation", The Journal of Strategic Information Systems, 22(4), 2013, pp. $257-$ 268.

[49] Majchrzak, A., C. Wagner, and D. Yates, "The impact of shaping on knowledge reuse for organizational improvement with wikis", Mis Quarterly, 37(2), 2013, pp. 455-469.

[50] O'reilly, T., "What is web 2.0", 2005.

[51] West, J. and S. O'mahony, "The role of participation architecture in growing sponsored open source communities", Industry and innovation, 15(2), 2008, pp. 145-168.

[52] Piezunka, H. and L. Dahlander, "Distant search, narrow attention: How crowding alters organizations' filtering of suggestions in crowdsourcing", Academy of Management Journal, 58(3), 2015, pp. 856-880.

[53] Lakhani, K.R. and J.A. Panetta, "The principles of distributed innovation", innovations, 2(3), 2007, pp. 97-112.

[54] Kunz, M., U. Bretschneider, and J.M. Leimeister, "Woohoo TinkerBots! The Marketing Effect of Crowdfunding", 2016.

[55] Blank, S., "Why the lean start-up changes everything", Harvard business review, 91(5), 2013, pp. 63-72.

[56] Pitt, L.F., R.T. Watson, P. Berthon, D. Wynn, and G. Zinkhan, "The penguin's window: Corporate brands from an open-source perspective", Journal of the Academy of Marketing Science, 34(2), 2006, pp. 115127.

[57] Pierce, J.L., T. Kostova, and K.T. Dirks, "Toward a theory of psychological ownership in organizations", Academy of management review, 26(2), 2001, pp. 298-310.

[58] Donaldson, T. and L.E. Preston, "The stakeholder theory of the corporation: Concepts, evidence, and implications", Academy of management review, 20(1), 1995, pp. 65-91.

[59] Jeppesen, L.B. and M.J. Molin, "Consumers as codevelopers: Learning and innovation outside the firm", Technology Analysis \& Strategic Management, 15(3), 2003, pp. 363-383.

[60] Prahalad, C.K. and V. Ramaswamy, "Co-opting customer competence", Harvard business review, 78(1), 2000, pp. 79-90.

[61] Hippel, E. von, "Democratizing innovation: The evolving phenomenon of user innovation", Journal für Betriebswirtschaft, 55(1), 2005, pp. 63-78. 